\title{
EVOLUÇÃO DA COBERTURA VEGETAL NOS LOTES RESIDENCIAIS PARTICULARES DOS BAIRROS SÍTIO CERCADO E JARDIM SOCIAL, CURITIBA - PR
}

\author{
Mariane Félix da Rocha
}

\author{
João Carlos Nucci
}

RESUMO: Este trabalho pretendeu analisar a relação dos proprietários de domicílios particulares de dois setores censitários de Curitiba - PR (um de alta escolaridade, localizado no bairro Jardim Social, e outro de baixa escolaridade, pertencente ao bairro Sítio Cercado), com o verde em seus lotes e averiguar se o nível de escolaridade desses proprietários interfere nessa relação. Isto é, buscou-se, na primeira etapa do trabalho, por meio de ferramentas da cartografia digital, avaliar se houve uma tendência entre os moradores dos setores censitários avaliados, no período compreendido entre 1999 e 2007, de manter, aumentar ou reduzir a cobertura vegetal de seus lotes. A segunda etapa do trabalho consistiu em perguntar aos proprietários, através da aplicação de questionários, a motivação dessas atitudes frente ao verde em seus lotes, e se há alguma influência da escolaridade nessas ações. Como resultado, obteve-se uma grande semelhança entre os dois setores censitários e ausência de alguma tendência de manutenção, redução ou aumento da cobertura vegetal nos lotes, bem como respostas relativamente parecidas dos proprietários quanto à motivação para modificar ou não a cobertura vegetal de seus lotes, tanto dentro de cada setor quanto comparando-os. Com isso se deduz que a escolaridade não teve influência significativa nas decisões dos proprietários.

PALAVRAS CHAVE: Cobertura vegetal. Lotes particulares. 


\section{INTRODUÇÃO}

A vegetação é um dos elementos que auxiliam na melhoria da qualidade ambiental no meio urbano. Neste ambiente, a vegetação aumenta o conforto térmico, reduz a poluição do ar e sonora, proporciona áreas onde a água infiltra para o solo, minimizando o risco e intensidade de enchentes, também traz maiores oportunidades de contato com a natureza para a população urbana, além de embelezar as cidades, podendo ser encontrada tanto em espaços públicos quanto privados.

Pereira (2004) constatou que $94,08 \%$ da área verde encontrada na bacia do Rio Belém, em Curitiba - PR estava em imóveis particulares, contra somente 5,92\% de áreas verdes localizadas em áreas públicas. Ainda segundo esse autor, os motivos que levaram os moradores a conservarem os bosques nativos e relevantes em seus imóveis foram principalmente os valores culturais, históricos, familiares e ecológicos, e não a redução do IPTU (Imposto Predial Territorial Urbano) que esta conservação pode trazer.

Mesmo que a pesquisa supracitada tenha tido como objeto de estudo os bosques nativos e relevantes ${ }^{1}$, ainda assim pode-se utilizá-la para destacar a importância para 0 meio ambiente urbano da conservação de todo tipo de vegetação em lotes particulares. Para que ocorra a manutenção ou retirada da cobertura vegetal em imóveis domiciliares, a decisão depende puramente dos proprietários desses imóveis, portanto, caso os proprietários optem por reduzir ou ampliar a cobertura vegetal de seus lotes, em grande escala, a perda ou ganho de vegetação urbana poderá ser considerável.

Essas questões motivaram esta pesquisa, que pretendeu averiguar os motivos que levaram os proprietários de casas térreas de dois setores censitários da capital

\footnotetext{
${ }^{1}$ De acordo com a lei $n^{\circ} 9.806 / 00$, o código florestal do município de Curitiba, citada em Pereira (2004), bosques nativos são conceituados como "maciços de mata nativa representativos da flora do município de Curitiba", que visem à preservação das águas, fauna, solos, paisagens e manutenção e distribuição equilibrada desses maciços (p. 36). Os bosques nativos são considerados relevantes se "pela tipologia florestal e localização estejam inscritos no cadastro do setor especial de áreas verdes junto à Secretaria Municipal de Meio Ambiente" (p. 36 e 37).
} 
paranaense a manter, reduzir ou aumentar a cobertura vegetal de seus lotes, bem como analisar se há uma tendência predominante com relação a isso nesses setores censitários comparando-se dois períodos: 1999 e 2007.

A escolha dos dois setores censitários levou em consideração a escolaridade de seus proprietários, a fim de também verificar se há relação entre a conservação da cobertura vegetal nos lotes e a escolaridade. Com isso se pretende fornecer subsídios à elaboração de estratégias ou ações que visem estimular os proprietários a conservar e até ampliar o verde em seus lotes.

\section{REVISÃO BIBLIOGRÁFICA}

Os problemas ambientais urbanos no Brasil, nas palavras de Osmar Pires Martins Júnior (1996, p. 27), "se agravaram em virtude da incapacidade de investimentos em infraestrutura e serviços capazes de compensar as desvantagens de ambientes densamente povoados" e piora devido à "insuficiente ou ausente cultura ambiental do cidadão da Urb". Alguns desses problemas ambientais urbanos citados pelo autor são o desmatamento de vertentes e encostas, que promove alterações geomorfológicas e ecológicas, a impermeabilização do solo, que contribui para a aridez do clima e enchentes, o lançamento de efluentes industriais e domésticos in natura em bacias hidrográficas, causando a poluição dos cursos d'água, e o aumento da poluição sonora e atmosférica, devido, sobretudo, ao intenso tráfego de veículos, que podem afetar a saúde da população (MARTINS JÚNIOR, 1996).

Vários dos aspectos supracitados (se não todos) são amenizados pela vegetação urbana, que desempenha um papel primordial na melhora da qualidade ambiental. No clima urbano, por exemplo, de acordo com Nucci (2008), a vegetação atua no sentido de reduzir os efeitos das ilhas de calor, causados pela impermeabilização do solo, que diminui a taxa de evaporação e aumenta a capacidade térmica da área, além de aumentar 
o risco de enchentes. Outros benefícios da vegetação nas cidades, citados pelo autor, são:

[...] estabilização de superfícies por meio da fixação do solo pelas raízes das plantas; obstáculo contra o vento; proteção da qualidade da água, pois impede que substâncias poluentes escorram para os rios; filtração do ar, diminuindo a poeira em suspensão; equilíbrio do índice de umidade no ar; redução do barulho; proteção das nascentes e dos mananciais; abrigo à fauna; organização e composição de espaços no desenvolvimento das atividades humanas; é um elemento de valorização visual e ornamental; estabilização da temperatura do ar; segurança das calçadas como acompanhamento viário; contato com a natureza colaborando com a saúde psíquica do homem, recreação [...] quebra da monotonia das cidades [...] consumo de vegetais e frutas frescas; estabelecimento de uma escala intermediária entre a humana e a construída. (Geiser et al., 1975 e 1976; Di Fidio, 1985; Marcus e Detwyler, 1972; Douglas, 1983; Cavalheiro, 1991; Fellenberg, 1980 e outros apud Nucci, 2008, p. 23-24).

Com relação aos benefícios trazidos pela vegetação à paisagem urbana, Mascaró e Mascaró (2002, p. 23) afirmaram que a presença da vegetação pode "formar uma cobertura vegetal aconchegante para quem passa por baixo de suas copas" e também minimizar a aridez da paisagem e melhorar sua ambiência ampliando psicologicamente 0 espaço urbano por meio do plantio de árvores em frente aos muros. A vegetação urbana também pode ser utilizada como complemento alimentar à população de baixa renda, por meio do plantio de árvores frutíferas ao longo de ruas e avenidas, como as mangueiras plantadas nas ruas principais da cidade de Belém do Pará (PA). De acordo com Mascaró e Mascaró (2002, p. 81), "associar as funções ambientais, principalmente a de sombreamento, às nutricionais, melhorará, sem dúvida, a comprometida ambiência dos bairros pobres da cidade". Outra função da vegetação que pode auxiliar na melhora tanto do ambiente urbano quanto da qualidade de vida da população é seu uso medicinal. $O$ plantio de espécies com essas propriedades, além de contribuir para o aumento do verde urbano, também pode auxiliar na redução dos gastos da população com remédios (MASCARÓ e MASCARÓ, 2002). Por todos esses papéis que a vegetação representa no meio urbano, é importante que todo tipo de verde nas cidades seja preservado ou ampliado, inclusive a vegetação de jardins e quintais. 


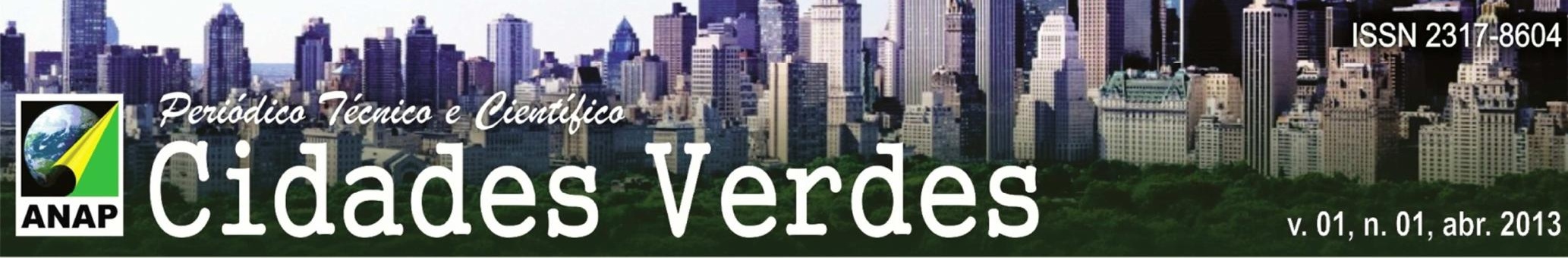

Para que haja a efetiva conservação do meio ambiente nos jardins, é necessário planejá-lo de modo a favorecer o valor ecológico em detrimento da beleza estética (PALAZZO JR. e BOTH, 1989). De acordo com Sipinski e Hoffmann (2010, p. 32), um "jardim nativo" pode ser conceituado como "uma proposta de jardinagem compatível com o meio ambiente, que valorize e dê prioridade à utilização de espécies nativas do ecossistema no qual ele está inserido". Planejar um jardim ecológico implica em analisar o espaço disponível na propriedade, o solo, a escolha das espécies e o manejo necessário. Deve-se também atentar não só para as plantas que compõe o ambiente natural, mas também para as relações que existem entre elas e os demais elementos (SIPINSKI e HOFFMANN, 2010). Palazzo Jr. e Both (1989) afirmam que os jardins ecológicos atraem aves, mamíferos, insetos, anfíbios e répteis, que contribuem com a polinização e no controle de pragas. Em um jardim ecológico, esses elementos interagem como num pequeno ecossistema.

Para aumentar a cobertura vegetal nos jardins, Grub (1986) apontou algumas sugestões. Além de árvores e arbustos, que já se sabe serem benéficos para o ambiente, o autor sugeriu o plantio de hortas, que protegem o solo e fornecem alimentos, vegetação em fachadas, que não substituem as árvores, mas contribuem para melhorar o clima urbano (e o equilíbrio térmico nas edificações), servem de alimento para a fauna, protegem as paredes da ação do tempo e necessitam de pouco espaço, técnica e recursos financeiros para serem mantidas. Grub (1986) também mostrou que é possível aumentar a cobertura vegetal nos lotes com vegetação nos telhados, desde que a construção tenha estrutura para suportar o peso da pequena camada de solo e de gramíneas (que devem ser preferencialmente de espécies resistentes às mudanças de temperatura e à composição do solo) e também substituindo as calçadas totalmente impermeabilizadas das garagens e acessos por pedras esparsas, para que a vegetação, mesmo que tímida, possa brotar e que também a água possa penetrar no solo.

É importante destacar que os termos comumente usados para se referir ao verde urbano (cobertura vegetal, áreas verdes e espaços livres) não são sinônimos e não desempenham a mesma função (CAVALHEIRO et al., 1999). O conceito de espaços livres de construção se refere a 
[...] espaços urbanos ao ar livre, destinados a todo tipo de utilização que se relacione com caminhadas, descanso, passeios, práticas de esporte e, em geral, a recreação e entretenimento em horas de ócio; os locais de passeios a pé devem oferecer segurança e comodidade com separação total da calçada em relação aos veículos; os caminhos devem ser agradáveis, variados e pitorescos; os locais onde as pessoas se locomovem por meios motorizados não devem ser considerados como espaços livres. (Cavalheiro et al., 1999)

Buccheri Filho e Tonetti (2010) complementam afirmando que os espaços livres de construção podem ser públicos (praças, parques) potencialmente coletivos (escolas com atividades recreativas aos fins de semana) ou privados (clubes esportivos). Um tipo especial de espaços livres são as áreas verdes, cujo elemento fundamental de composição é a vegetação. Para Cavalheiro et al. (1999), uma área verde deve cumprir três funções principais: ecológico-ambiental, estética e de lazer. Buccheri Filho e Tonetti (2010, p. 65) citaram como exemplos da função ecológica das áreas verdes a

[...] estabilização de determinadas superfícies, obstáculo contra o vento, proteção da qualidade da água, filtração do ar, equilíbrio do índice de umidade, redução dos ruídos, suporte para a fauna, etc. A função estética relaciona-se com a diversidade de emoções e sentimentos que a área verde suscita.

Já o termo cobertura vegetal "é a projeção do verde em cartas planimétricas e pode ser identificada por meio de fotografias aéreas, sem auxílio de esteroscopia" (CAVALHEIRO et al, 1999). Diferentemente do que ocorre na identificação de áreas verdes, pode ser considerado nesse termo o verde encontrado nas Unidades de Conservação (que geralmente restringem 0 acesso da população), nos espaços construídos e nos espaços de integração (vias), e não somente o que há nos espaços livres. 


\section{METODOLOGIA}

\subsection{ESCOLHA DO RECORTE ESPACIAL}

O setor censitário foi escolhido como recorte espacial em função de o IBGE disponibilizar os dados de escolaridade (dado relevante para a pesquisa) por setor censitário e também devido à necessidade de abranger uma menor área, uma vez que foram analisados os imóveis um a um, sendo, por isso, inviável optar por um recorte espacial muito abrangente.

A fim de analisar se há relação entre a conservação da cobertura vegetal nos imóveis e o nível de escolaridade dos proprietários, foram escolhidos dois setores censitários do município de Curitiba (figura 1): o setor número 410690205010307, localizado no bairro Jardim Social, cuja média de escolaridade, de 14,41 anos de estudo para cada proprietário, é uma das mais altas da cidade (figura 2) e o de número 410690205080076, pertencente ao bairro Sítio Cercado, que possui baixos índices de escolaridade, com uma média de 7,01 anos de estudo por proprietário (figura 3). Outro motivo para a escolha desses setores foi o fato de predominarem casas térreas em ambos. Isto porque, em casas térreas, as modificações na cobertura vegetal são fruto das decisões dos proprietários, diferentemente do que ocorre em prédios ou condomínios, que geralmente tem seus espaços livres planejados sem que os proprietários tenham um controle direto sobre isso. 

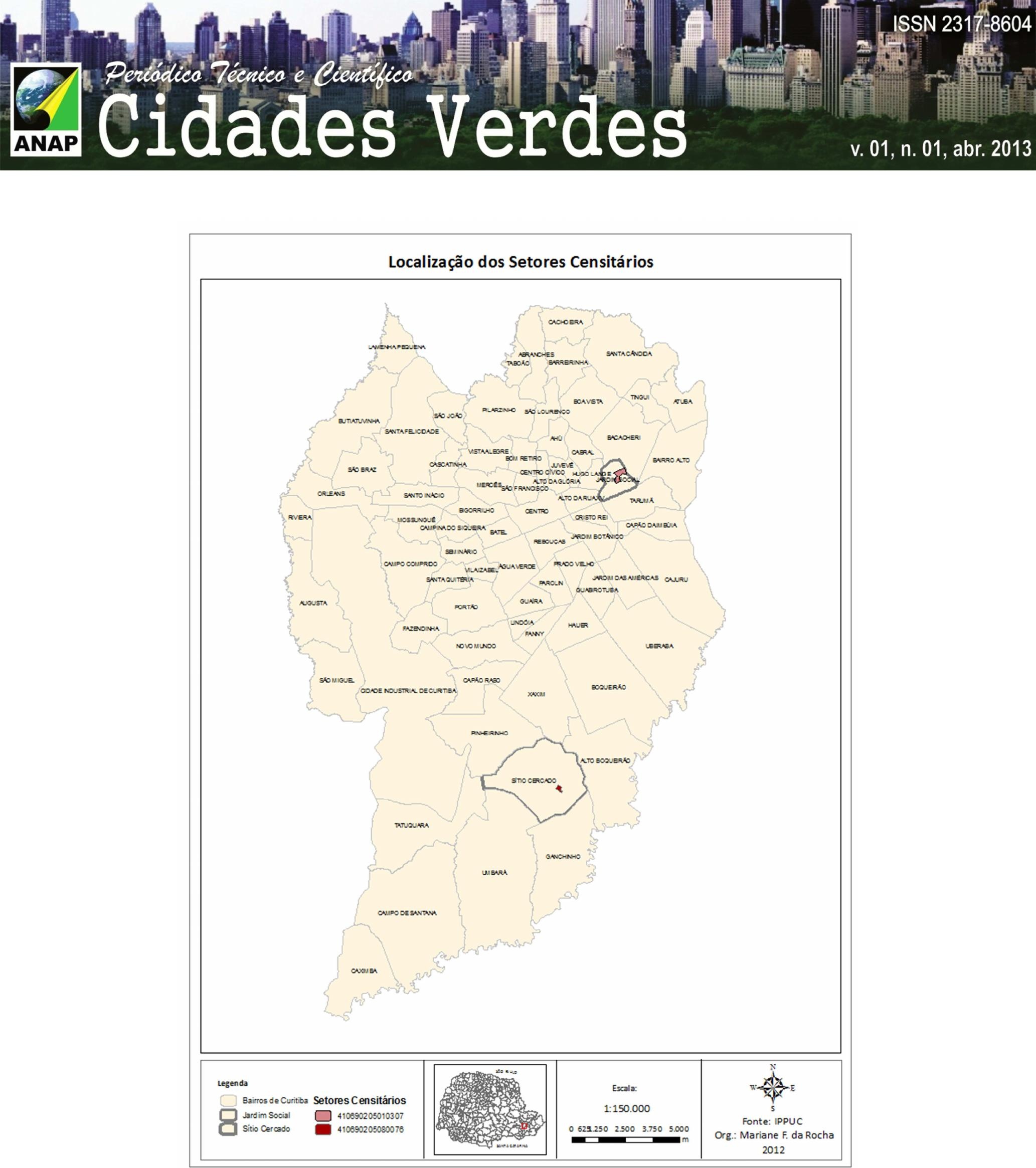

FIGURA 1 - LOCALIZAÇÃO DOS SETORES CENSITÁRIOS ANALISADOS.

FONTE: Rocha (2012). 

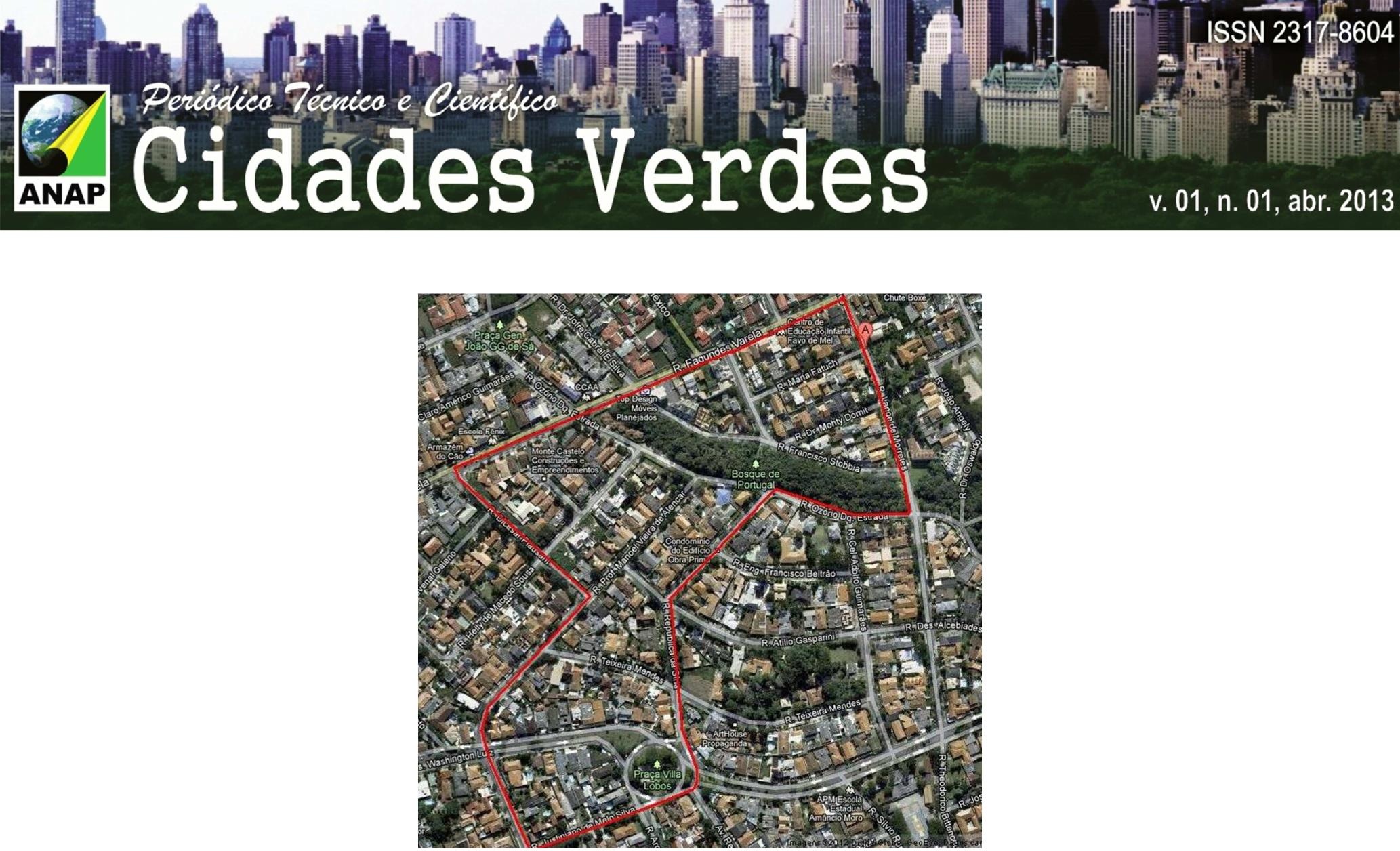

FIGURA 2 - SETOR CENSITÁRIO, PERTENCENTE AO BAIRRO JARDIM SOCIAL, DE ALTA ESCOLARIDADE CONSIDERADO PARA A PESQUISA

FONTE - IBGE (2000); Google Maps (2009). Org.: Rocha (2012).

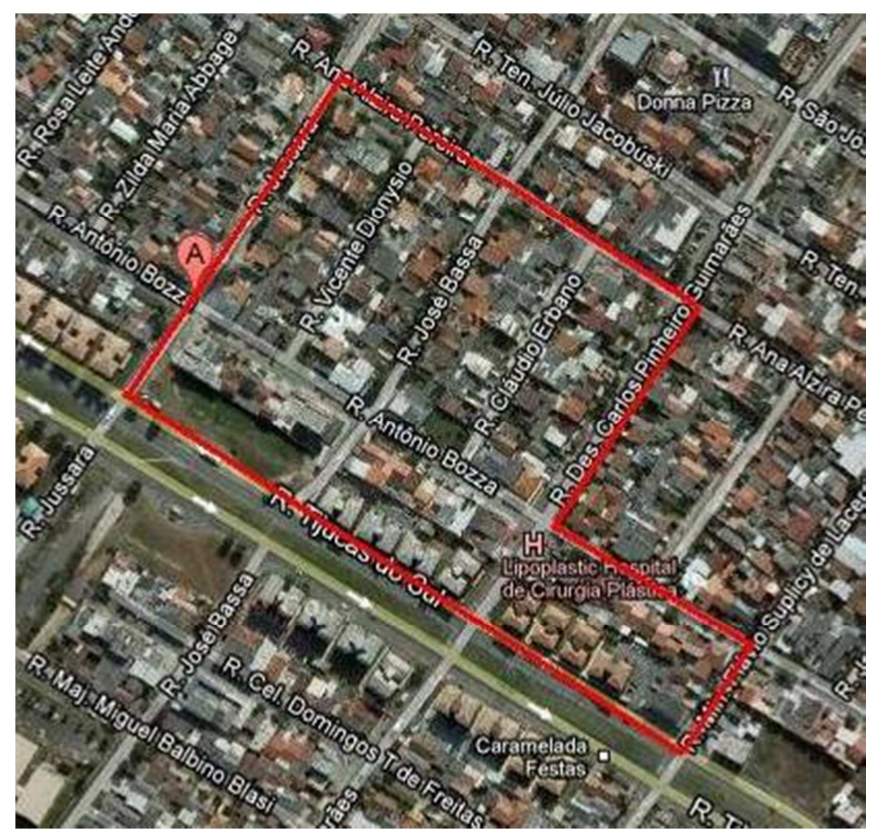

FIGURA 3 - SETOR CENSITÁRIO, PERTENCENTE AO BAIRRO SÍTIO CERCADO, DE BAIXA ESCOLARIDADE CONSIDERADO PARA A PESQUISA.

FONTE: IBGE (2000); Google Maps (2009). Org.: Rocha (2012). 


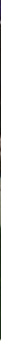

\subsection{UTILIZAÇÃO DE SIG E FOTOGRAFIAS AÉREAS}

Com o auxílio do software ArcGIS 9.3.1 e utilizando as fotografias aéreas cedidas pelo IPPUC, dos períodos de 1999 (escala 1:8.000) e 2007 (escala 1: 2.000), foi feita a comparação da cobertura vegetal que havia em cada lote (figura 4), na escala aproximada de 1:400.
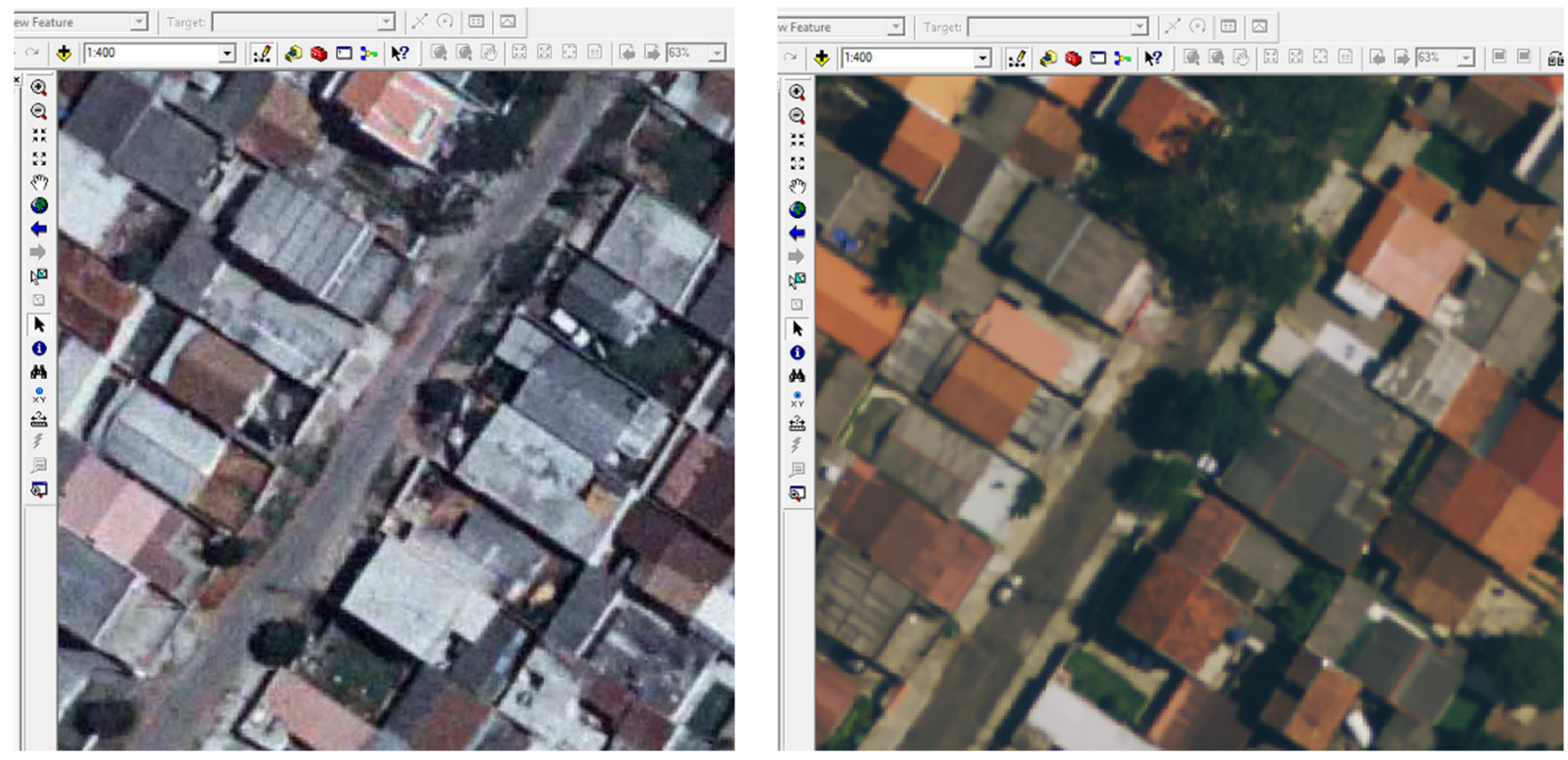

FIGURA 4 - EXEMPLO DE VISUALIZAÇÃO DAS FOTOGRAFIAS AÉREAS DE 1999 E 2007 NOS LOTES DO SETOR CENSITÁRIO DO BAIRRO SíTIO CERCADO NA ESCALA APROXIMADA DE 1:400. FONTE: Fotografias aéreas do IPPUC (1999). Org.: Rocha (2012).

Com base nessas duas fotografias aéreas, constatava-se, para cada lote, se houve a redução, aumento ou manutenção da cobertura vegetal, considerando-se toda a área do lote, inclusive a parte frontal (que fica externo à área murada), e então os lotes 

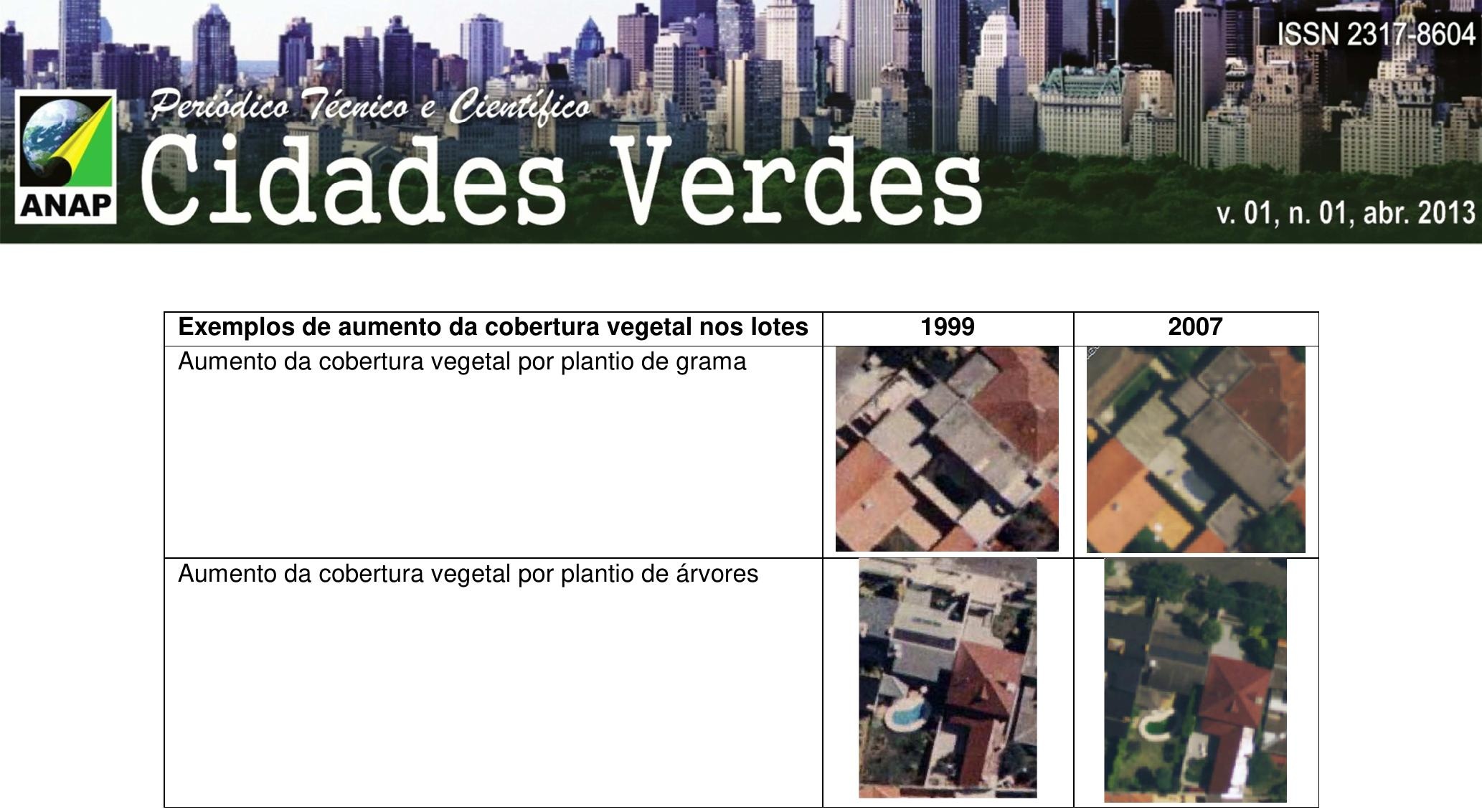

QUADRO 1 - EXEMPLOS DE AUMENTO DA COBERTURA VEGETAL NOS LOTES.

FONTE: Fotografias aéreas do IPPUC (1999 e 2007). Org.: Rocha (2012).

Para conceituar o que seria considerado redução da cobertura vegetal, utilizou-se a fórmula supracitada invertida: se um proprietário construiu ou fez calçada sobre uma área gramada/ arborizada ou de solo exposto, retirou ou podou as árvores de seu lote ou fez outras alterações que fizessem com que a cobertura vegetal do lote visualmente fosse reduzida, seu lote foi classificado como perda de cobertura vegetal (quadro 2).

\begin{tabular}{|l|l|l|l|}
\hline Exemplos de redução da cobertura vegetal nos lotes & & \\
\hline $\begin{array}{l}\text { Redução da cobertura vegetal por construção sobre } \\
\text { gramado }\end{array}$ & \\
\hline Redução da cobertura vegetal por corte de árvores & & \\
\hline
\end{tabular}

QUADRO 2 - EXEMPLOS DE REDUÇÃO DA COBERTURA VEGETAL NOS LOTES.

FONTE: Fotografias aéreas do IPPUC (1999 e 2007). Org.: Rocha (2012). 


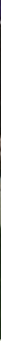

A manutenção da cobertura vegetal nos lotes foi considerada nos casos em que não foi feita nenhuma alteração no lote (incluindo-se os lotes que em 1999 não possuíam nenhum verde e mantiveram essa situação em 2007) ou cujas modificações se "compensaram": houve perda de grama em uma parte do lote e plantio em outra; foi feito o calçamento de uma parte de grama, mas também foram plantadas árvores, etc. (quadro 3).

\begin{tabular}{|l|l|}
\hline Exemplos de manutenção da cobertura vegetal nos lotes \\
\hline Sem cobertura vegetal em ambos os períodos \\
\hline Manutenção da cobertura vegetal em terreno baldio
\end{tabular}

QUADRO 3 - EXEMPLOS DE MANUTENÇÃO DA COBERTURA VEGETAL NOS LOTES.

FONTE: Fotografias aéreas do IPPUC (1999 e 2007). Org.: Rocha (2012).

Obviamente as decisões dos proprietários não podem ser rigorosamente classificadas somente pela lógica proposta pela "fórmula" de análise da perda ou aumento da cobertura vegetal. Dessa forma, a estruturação dessa "fórmula" serviu como referência para analisar o que tem um peso maior na melhora ou piora da qualidade ambiental 
urbana entre árvores, gramado, solo exposto e calçada/ construções, por isso a cobertura vegetal demonstrada visualmente pelas fotografias aéreas contribuiu grandemente para a classificação.

Um detalhe que deve ser destacado aqui é o caso das árvores que estão entre dois lotes. Nesses casos, quando era possível atribuir em qual terreno a árvore estava plantada, ela era considerada inteiramente pertencente a esse terreno (ou seja, por mais que seus galhos se estendessem para o lote vizinho, eles não eram considerados na análise desse lote). Somente foram consideradas pertencentes a dois ou mais lotes as árvores que não foram possíveis de distinguir a qual lote pertenciam e, nesses casos, o crescimento, poda ou retirada da árvore foram considerados para análise de todos os lotes envolvidos.

\subsection{APLICAÇÃO DOS QUESTIONÁRIOS}

Questionários foram aplicados para verificar os motivos que levam os proprietários a modificar ou não a cobertura vegetal de seus lotes. As perguntas buscavam saber:

- A escolaridade do proprietário;

- Há quanto tempo a família reside no imóvel;

- Se, na visão do proprietário, houve aumento, redução ou manutenção da área de quintal/ jardim/ com grama/ com árvores/ com horta no lote no período em que os moradores residiam na casa;

- Por que foram realizadas essas alterações no lote ou, em caso de manutenção da cobertura vegetal, por que não foram feitas modificações;

- Se a parte do terreno externa à casa ainda sofrerá mudanças e, se sim, quais serão elas. 
A aplicação dos questionários foi efetuada da seguinte maneira: com o auxílio de um mapa de campo de cada setor censitário, com o arruamento e os lotes numerados (figura 5), os moradores eram chamados, casa por casa, pela autora e, caso aceitassem participar da pesquisa, respondiam às questões e marcava-se um "ok" em cima do lote, no mapa de campo, para registrar que aquele lote não precisava ser revisitado na próxima semana.

Nas residências em que não havia moradores presentes ou tivessem moradores que não sabiam responder ao questionário, este era colocado na caixa de correio, com uma breve descrição da pesquisa e o e-mail da pesquisadora caso o proprietário preferisse enviar as respostas por e-mail. Marcava-se um asterisco sobre o lote, no mapa de campo, para identificar que aquele lote deveria ser revisitado. No sábado seguinte, se não obtivesse resposta por e-mail, a pesquisadora retornava à residência em questão para buscar o questionário e, caso a residência novamente estivesse vazia, riscava-se um "X" sobre o lote no mapa de campo, para registrar que aquele proprietário não foi encontrado. A mesma marca era utilizada nos lotes onde o proprietário não quis participar da pesquisa, quando se tratava de lotes comerciais, prédios, terrenos baldios, casas em construção ou sem caixa de correio.

No setor censitário do Sítio Cercado, por ser pequeno (composto por 150 lotes), todos os seus proprietários foram procurados. Já no setor censitário do Jardim Social, apenas os proprietários que moram ao sul do Bosque de Portugal responderam à pesquisa (figura 5), totalizando também 150 lotes nessa área. 

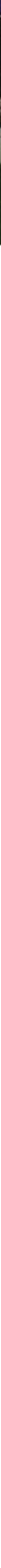

FIGURA 5 - MAPA DE CAMPO DO SETOR CENSITÁRIO DO JARDIM SOCIAL; NO DESTAQUE: LOTES CONSIDERADOS PARA A APLICAÇÃO DOS QUESTIONÁRIOS NO SETOR CENSITÁRIO DO JARDIM SOCIAL.

FONTE: Rocha (2012). 


\section{RESULTADOS}

\subsection{COMPARAÇÃO DA COBERTURA VEGETAL NOS LOTES}

No setor censitário localizado no bairro Sítio Cercado, por meio da comparação da cobertura vegetal retratada nas fotografias aéreas, em cada lote, constatou-se que, dos 150 lotes do setor: 48 aumentaram a cobertura vegetal de 1999 para 2007 (32\%); 43 lotes mantiveram a cobertura vegetal no período (29\%); 50 lotes perderam cobertura vegetal (33\%); e 9 lotes não tiveram classificação (6\%). Com isso, percebe-se que, nesse setor, não houve uma tendência predominante de aumento, redução ou manutenção da cobertura vegetal. Pelo contrário, as três categorias praticamente "empataram", embora a perda de cobertura vegetal tenha levemente se sobressaído, seguida do aumento da cobertura vegetal e, por último, a manutenção (figura 6). 

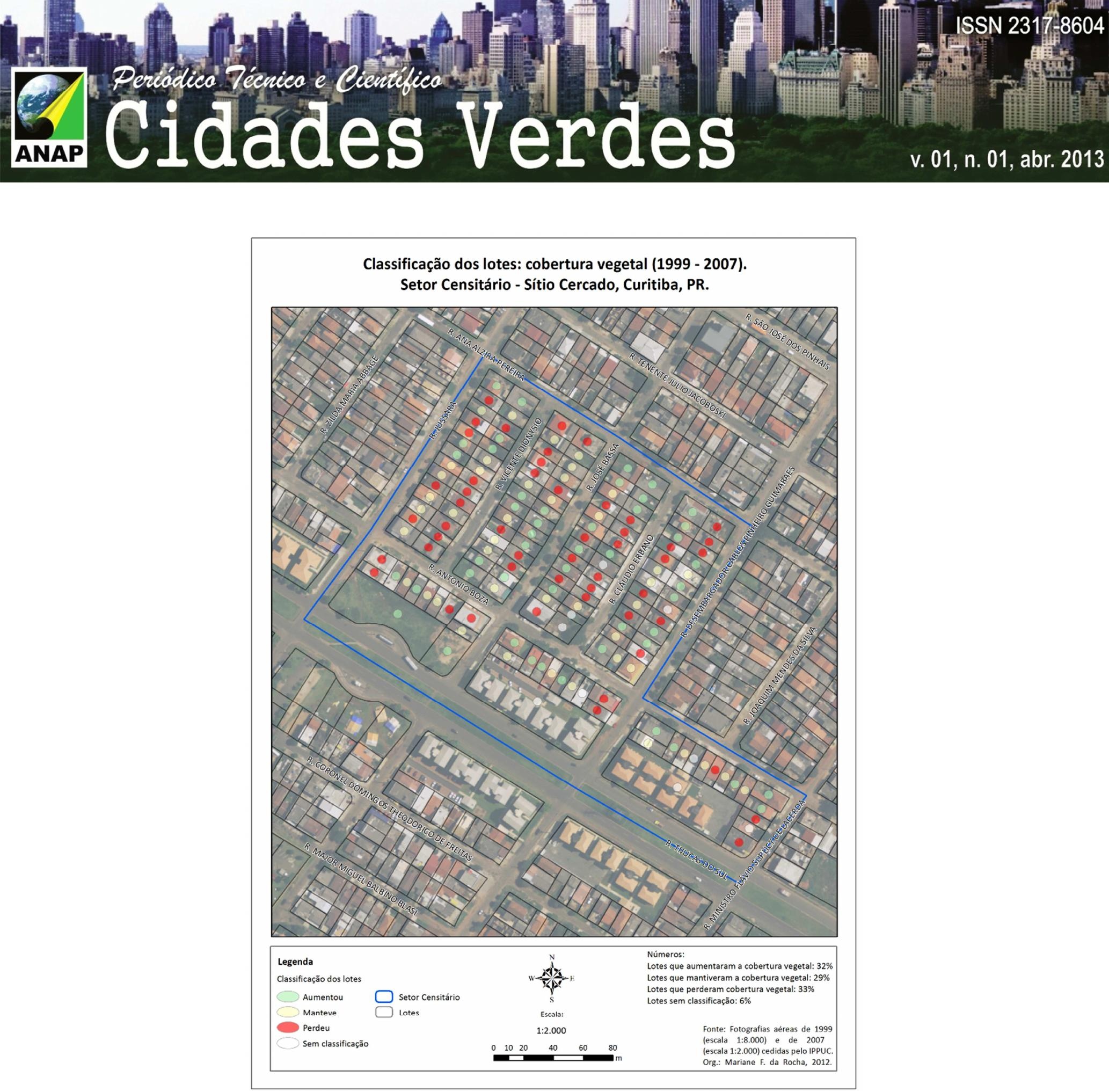

FIGURA 6 - CLASSIFICAÇÃO DOS LOTES DO SETOR CENSITÁRIO DO SÍTIO CERCADO. FONTE: Rocha (2012).

No setor censitário pertencente ao bairro Jardim Social, dos 216 lotes analisados, 61 aumentaram sua cobertura vegetal na comparação entre os períodos (28\%); 54 lotes mantiveram sua cobertura vegetal entre 1999 e 2007 (25\%); 62 lotes perderam cobertura vegetal (29\%); e 39 lotes foram considerados sem classificação (18\%). Da mesma forma que ocorreu com o setor censitário do Sítio Cercado, aqui também não houve predomínio 


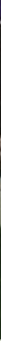

de nenhuma tendência (aumento, manutenção ou redução) dos proprietários com relação à cobertura vegetal em seus lotes, havendo porcentagens bastante semelhantes entre as opções. Nesse setor também, a perda de cobertura vegetal foi levemente maior que as outras porcentagens, ficando o aumento da cobertura vegetal novamente com o segundo lugar e a manutenção em último (figura 7).

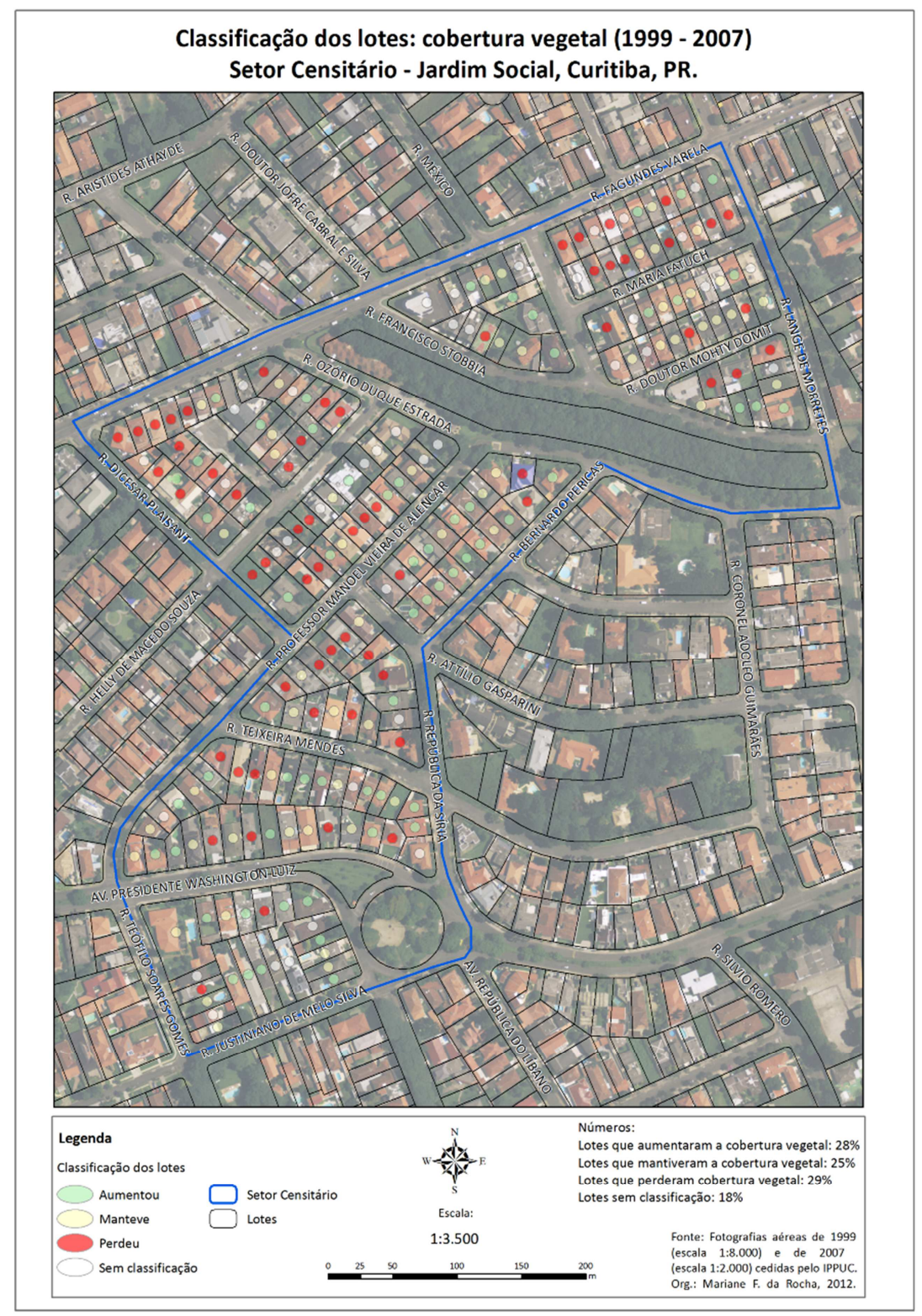

FIGURA 7 - CLASSIFICAÇÃO DOS LOTES DO SETOR CENSITÁRIO DO JARDIM SOCIAL. FONTE: Rocha (2012). 
Com a contagem dos lotes de cada classe dos dois setores notou-se que ambos tiveram resultados muito semelhantes no que diz respeito à conservação ou não do verde nos lotes domiciliares particulares (quadro 4), a despeito de os moradores do setor censitário do Jardim Social terem o dobro de anos de estudo comparados aos moradores do setor censitário do Sítio Cercado. Com base nisso, infere-se que a escolaridade não teve influência significativa nas decisões dos proprietários com relação à cobertura vegetal em seus terrenos.

Ao excluir da contagem os lotes sem classificação ${ }^{2}$ constatou-se que os resultados obtidos mantêm a mesma proporção entre aumento, redução e manutenção da cobertura vegetal em cada setor e, na comparação entre os dois setores, fica ainda mais evidente a semelhança dos resultados (quadro 4).

\begin{tabular}{|l|c|c|c|c|}
\hline \multicolumn{5}{|c|}{ Comparação dos resultados - considerando os lotes sem classificação } \\
\hline & Aumentou & Manteve & Diminuiu & Sem classificação \\
\hline Sítio Cercado & $32 \%$ & $29 \%$ & $33 \%$ & $6 \%$ \\
\hline Jardim Social & $28 \%$ & $25 \%$ & $29 \%$ & $18 \%$ \\
\hline \multicolumn{2}{|c|}{ Comparação dos resultados - desconsiderando os lotes sem classificação } \\
\hline Sítio Cercado & $34 \%$ & $31 \%$ & $35 \%$ & - \\
\hline Jardim Social & $34 \%$ & $31 \%$ & $35 \%$ & - \\
\hline
\end{tabular}

QUADRO 4 - COMPARAÇÃO DOS RESULTADOS DOS DOIS SETORES CENSITÁRIOS. FONTE: Rocha (2012).

\subsection{ANÁLISE DOS QUESTIONÁRIOS}

\footnotetext{
${ }^{2}$ Isto é, considerou-se para o setor censitário do Sítio Cercado um total de 141 lotes e para o setor do Jardim Social, 177 lotes.
} 


\subsubsection{Escolaridade}

No setor censitário do Jardim Social, a maioria dos proprietários possuía ensino superior completo ou pós-graduação (84\%), enquanto no setor censitário do Sítio Cercado quase metade dos proprietários não chegaram a concluir o ensino médio (49\%). Com base nisso, percebe-se que é grande a diferença de escolaridade dos proprietários entrevistados entre os dois setores (quadro 5).

\begin{tabular}{|c|c|c|c|c|}
\hline \multirow[t]{2}{*}{ Escolaridade } & \multicolumn{2}{|c|}{ Sítio Cercado } & \multicolumn{2}{|c|}{ Jardim Social } \\
\hline & $\mathrm{n}^{0}$ & $\%$ & $\mathrm{n}^{\circ}$ & $\%$ \\
\hline Ens. fundamental incompleto & 18 & 25 & - & - \\
\hline Ens. fundamental completo & 11 & 15 & - & - \\
\hline Ens. médio incompleto & 6 & 9 & - & - \\
\hline Ens. médio completo & 26 & 37 & 5 & 9 \\
\hline Ens. superior incompleto & 6 & 9 & 4 & 7 \\
\hline Ens. superior completo & 3 & 4 & 39 & 67 \\
\hline Pós-graduação & 1 & 1 & 10 & 17 \\
\hline TOTAIS & 71 & $100 \%$ & 58 & $100 \%$ \\
\hline
\end{tabular}

QUADRO 5 - ESCOLARIDADE DOS PROPRIETÁRIOS ENTREVISTADOS DE AMBOS OS SETORES CENSITÁRIOS.

FONTE: Rocha (2012).

\subsubsection{Tempo de residência no imóvel}

Quanto ao tempo de residência no imóvel, em ambos os setores censitários a maioria dos moradores entrevistados reside no mesmo lote há mais de 13 anos (quadro 
6), ou seja, trata-se da mesma família proprietária desde 1999, ano da fotografia aérea mais antiga utilizada na análise da evolução da cobertura vegetal nos terrenos na etapa anterior do trabalho.

\begin{tabular}{|l|c|c|c|c|}
\hline \multirow{2}{*}{ Tempo de residência no imóvel } & \multicolumn{2}{|l|}{ Sítio Cercado } & \multicolumn{2}{l|}{ Jardim Social } \\
\cline { 2 - 5 } & $n^{\circ}$ & $\%$ & $n^{\circ}$ & $\%$ \\
\hline Até 12 anos & 29 & 41 & 27 & 47 \\
\hline Mais de 13 anos & 42 & 59 & 31 & 53 \\
\hline TOTAIS & 71 & $100 \%$ & 58 & $100 \%$ \\
\hline
\end{tabular}

QUADRO 6 - TEMPO DE RESIDÊNCIA NO IMÓVEL DOS PROPRIETÁRIOS ENTREVISTADOS DE AMBOS OS SETORES CENSITÁRIOS.

FONTE: Rocha (2012).

\subsubsection{Evolução da cobertura vegetal dos lotes}

Nos dois setores censitários analisados a maioria dos proprietários acreditava que a cobertura vegetal de seus lotes manteve-se a mesma no período em que residiam no imóvel (quadro 7).

\begin{tabular}{|l|c|c|c|c|}
\hline \multirow{2}{*}{ Cobertura vegetal nos lotes } & \multicolumn{2}{|c|}{ Sítio Cercado } & \multicolumn{2}{c|}{ Jardim Social } \\
\cline { 2 - 5 } & $n^{\circ}$ & $\%$ & $n^{\circ}$ & $\%$ \\
\hline Aumentou & 12 & 17 & 18 & 31 \\
\hline Manteve & 32 & 45 & 33 & 57 \\
\hline Reduziu & 27 & 38 & 7 & 12 \\
\hline TOTAIS & 71 & $100 \%$ & 58 & $100 \%$ \\
\hline
\end{tabular}

QUADRO 7 - EVOLUÇÃO DA COBERTURA VEGETAL NOS LOTES DE ACORDO COM OS PROPRIETÁRIOS.

FONTE: Rocha (2012). 
Ao responder sobre a evolução da cobertura vegetal em seus terrenos, percebeuse, pelas respostas, que muitos proprietários consideraram mais o conceito de área verde que o de cobertura vegetal. Por isso, é comum que um lote classificado neste trabalho como tendo aumentado sua cobertura vegetal pelo plantio de árvores, para o proprietário foi considerado manutenção, pois não teve aumento da área verde do lote. O contrário também foi percebido: o corte de árvore sem alteração na área de gramado, por exemplo, para muitos proprietários foi considerado manutenção da cobertura vegetal. Como as respostas foram livres, não foram feitas interrupções ou explicações aos proprietários no momento da aplicação dos questionários. Ademais, para responder a essa questão, os proprietários consideraram todo o período em que residiam no lote, isto é, na análise deles, também foi considerado o período de 2007 a 2012, que não foi contemplado na etapa anterior deste trabalho.

\subsubsection{Manutenção da cobertura vegetal nos lotes}

No setor censitário do bairro Sítio Cercado, dentre os motivos apontados pelos proprietários para manter a cobertura vegetal, o mais citado foi a falta de espaço (7 respostas), seguido de a casa ser alugada (não sendo possível, por isso, fazer modificações), e o gosto pessoal (4 respostas cada um). 


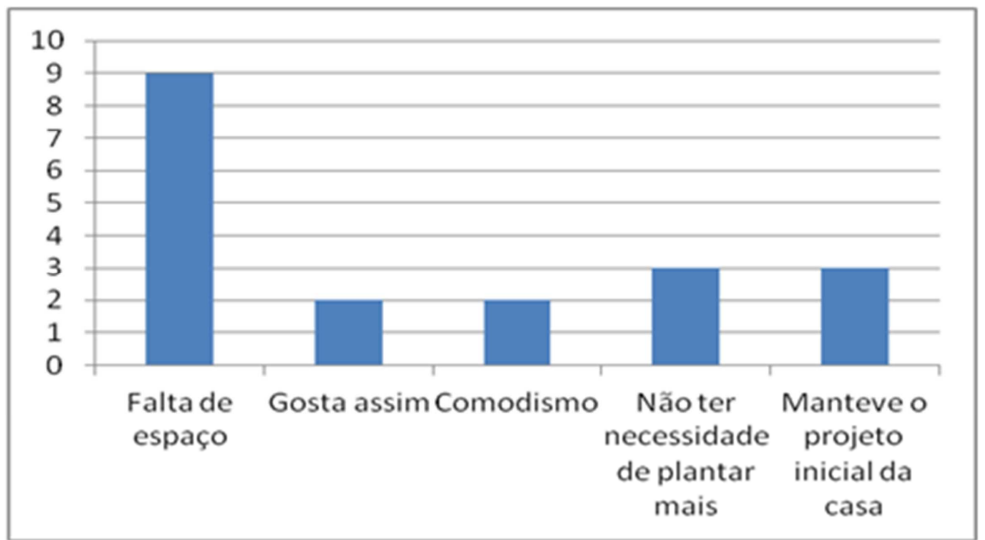

FIGURA 9 - PRINCIPAIS MOTIVOS APONTADOS PELOS PROPRIETÁRIOS PARA MANTER A COBERTURA VEGETAL EM SEUS LOTES - SETOR CENSITÁRIO DO JARDIM SOCIAL.

FONTE: Rocha (2012).

Outros motivos mencionados pelos proprietários de imóveis no setor censitário do Jardim Social para manter a cobertura vegetal em seus lotes foram: trabalhar fora e não ter tempo de cuidar; não plantar mais árvores pra não sombrear demais o lote; e utilizar o gramado para jogar futebol (por isso não plantam mais árvores).

\subsubsection{Aumento da cobertura vegetal nos lotes}

Dos motivos apontados para aumentar a cobertura vegetal nos lotes, foram mencionados mais de uma vez pelos proprietários entrevistados do setor censitário do Sítio Cercado somente gostar de árvores, flores e plantas e plantar horta. 


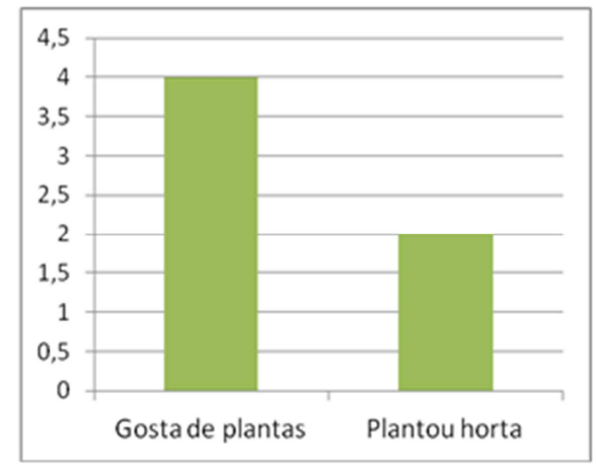

FIGURA 10 - PRINCIPAIS MOTIVOS APONTADOS PELOS PROPRIETÁRIOS PARA AUMENTAR A COBERTURA VEGETAL EM SEUS LOTES - SETOR CENSITÁRIO DO SÍTIO CERCADO.

FONTE: Rocha (2012).

Outros motivos/ações citados(as) pelos proprietários de imóveis nesse setor para o aumento da cobertura vegetal foram: embelezamento; colocaram vasos com flores (não tem espaço para aumentar a cobertura vegetal); porque não pode ter o lote todo construído.

Gostar de plantas também foi o motivo principal apontado pelos moradores do setor censitário do Jardim Social para aumentar o verde em seus lotes (figura 11), mas vários outros motivos também foram mencionados, tais como o cultivo de orquídeas, a infiltração de água no solo, a preservação ambiental e o proprietário ser ambientalista.

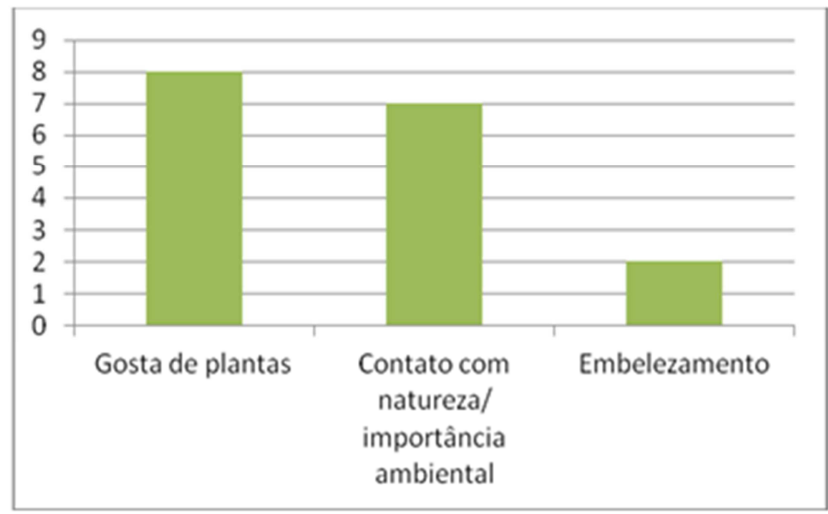

FIGURA 11 - PRINCIPAIS MOTIVOS APONTADOS PELOS PROPRIETÁRIOS PARA AUMENTAR A COBERTURA VEGETAL EM SEUS LOTES - SETOR CENSITÁRIO DO JARDIM SOCIAL.

FONTE: Rocha (2012). 
Comparando-se os motivos citados pelos moradores do Jardim Social para o aumento do verde em seus lotes com os motivos apontados pelos moradores do Sítio Cercado, notou-se que, aparentemente, aqueles aumentaram a cobertura vegetal mais focados nas questões ambientais do que estes. Possivelmente, aqui aparece a diferença da escolaridade: ela pode não influenciar massivamente os proprietários a aumentarem a cobertura vegetal em seus lotes, mas quem o faz geralmente tem essa consciência.

\subsubsection{Redução da cobertura vegetal nos lotes}

No setor censitário pertencente ao Sítio Cercado, os proprietários entrevistados apontaram como principal motivo para a redução da cobertura vegetal nos imóveis o calçamento (11), devido a diversos motivos, seguido de construção (7).

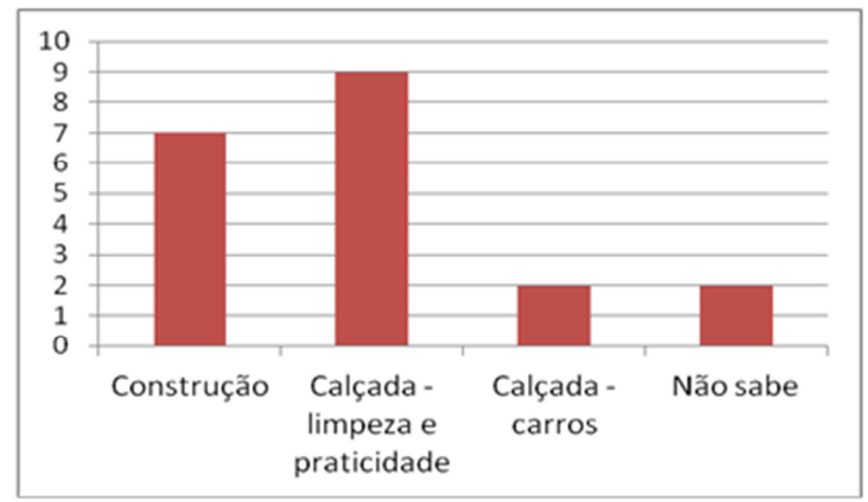

FIGURA 12 - PRINCIPAIS MOTIVOS APONTADOS PELOS PROPRIETÁRIOS PARA REDUZIR A COBERTURA VEGETAL EM SEUS LOTES - SETOR CENSITÁRIO DO SÍTIO CERCADO.

FONTE: Rocha (2012). 
Percebe-se a importância do calçamento na perda da cobertura vegetal dos lotes, principalmente devido à sua praticidade para limpar e conservar. Um ponto interessante mostrado pela figura 12 é o fato de dois proprietários simplesmente não saberem por que reduziram o verde em seus lotes.

O quadro 8 traz outros motivos destacados pelos moradores do setor censitário do Sítio Cercado para reduzir a cobertura vegetal de seus terrenos.

\begin{tabular}{|l|}
\hline A árvore oferecia risco. \\
\hline Um funcionário da prefeitura matou a árvore com uma poda errada. \\
\hline Fez calçada na parte externa do lote para os pedestres. \\
\hline Corte de árvore por decisão da prefeitura. \\
\hline A calçada é mais limpa do que terra e grama. \\
\hline Cortou a árvore da frente porque atrapalhava a entrada da casa e não tem espaço para plantar outra árvore. \\
\hline Havia muito barro - se arrependeu de ter feito calçamento em uma área tão grande. \\
\hline Trocou a grama por calçada - haviam muitas aranhas. \\
\hline Podou a árvore por causa dos fios de luz e colocou pedras sobre a grama para não precisar cortá-la. \\
\hline
\end{tabular}

QUADRO 8 - MOTIVOS APONTADOS PELOS PROPRIETÁRIOS PARA REDUZIR A COBERTURA VEGETAL EM SEUS LOTES - SETOR CENSITÁRIO DO SÍTIO CERCADO.

FONTE: Rocha (2012).

O único motivo citado pelos moradores do setor censitário do Jardim Social para reduzir a cobertura vegetal de seus lotes foi a construção ou reforma (da casa, garagem, edículas e/ou piscinas).

\subsubsection{Futura evolução da cobertura vegetal dos lotes}

Quanto ao futuro da parte externa à casa, isto é, a parte de terreno sem construção, no setor censitário do Sítio Cercado 39\% dos proprietários pretendiam mudar essa parte do lote (quadro 9). 


\begin{tabular}{|l|c|c|c|c|}
\hline \multirow{2}{*}{$\begin{array}{l}\text { Modificações futuras na parte } \\
\text { externa à casa }\end{array}$} & \multicolumn{2}{|c|}{ Sítio Cercado } & \multicolumn{2}{c|}{ Jardim Social } \\
\cline { 2 - 5 } & $n^{\circ}$ & $\%$ & $n^{\circ}$ & $\%$ \\
\hline Sim & 28 & 39 & 9 & 16 \\
\hline Não & 43 & 61 & 48 & 83 \\
\hline Não sabe & - & - & 1 & 1 \\
\hline TOTAIS & 71 & $100 \%$ & 58 & $100 \%$ \\
\hline
\end{tabular}

QUADRO 9 - NÚMERO DE PROPRIETÁRIOS QUE PRETENDEM E NÃO PRETENDEM FAZER MODIFICAÇÕES EM SEUS LOTES.

FONTE: Rocha (2012).

Das mudanças a serem realizadas, a maioria iria reduzir a cobertura vegetal do lote (figura 13), seguida por modificações que aumentariam a cobertura vegetal. As demais manteriam a cobertura vegetal (como colocação de cerâmica sobre calçadas que já tem no lote ou aumento da casa para cima, sem modificar a parte externa à casa).

Já no setor censitário pertencente ao bairro Jardim Social, apenas 16\% dos proprietários pretendiam fazer modificações no lote e 1\% não sabiam (quadro 9). Das modificações que os proprietários pretendiam fazer em seus terrenos, a maioria ocasionaria o aumento da cobertura vegetal (figura 13). Entre as modificações a serem realizadas que manteriam a cobertura vegetal estariam a colocação de um cercado para o cachorro, arrumação da calçada que está quebrada e alteração da espécie de árvore, deformada devido aos erros na poda e não ser a mais adequada para ocupar vias públicas (a princípio, não representaria perda nem ganho de cobertura vegetal). 
dois proprietários que utilizariam paralelepípedo, segundo um deles, justamente por permitir a infiltração da água no solo. Um dos proprietários que pretendia fazer calçada em seu lote afirmou que foi uma exigência da prefeitura da cidade, para os pedestres.

No setor censitário do Jardim Social, a única modificação apontada por um proprietário que reduziria a cobertura vegetal no lote seria o corte das árvores que estivessem velhas.

Das modificações que aumentariam o verde nos lotes do setor censitário do Sítio Cercado, o plantio de grama é o mais citado, seguido do plantio de horta (figura 15).

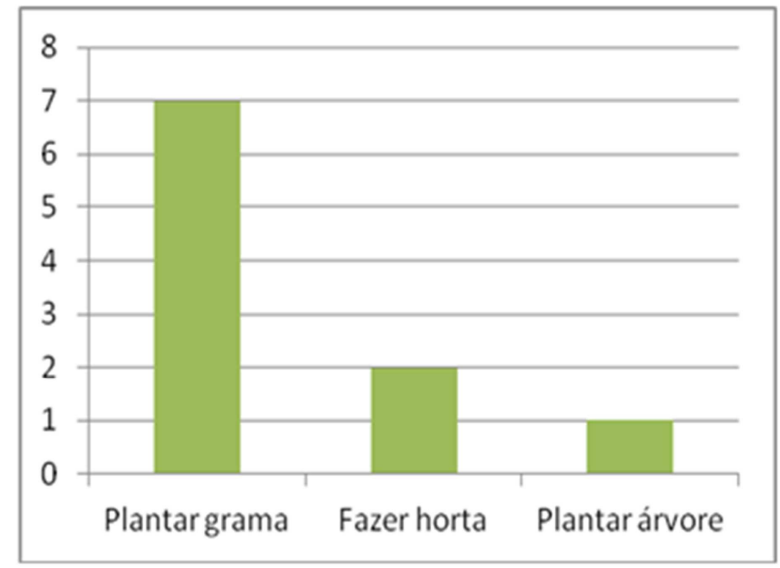

FIGURA 15 - MODIFICAÇÕES A SEREM FEITAS NOS LOTES QUE OCASIONARÃO O AUMENTO DA COBERTURA VEGETAL - SETOR CENSITÁRIO DO SÍTIO CERCADO.

FONTE: Rocha (2012).

No setor censitário do Jardim Social, as modificações que aumentariam a cobertura vegetal são representadas na figura 16. 


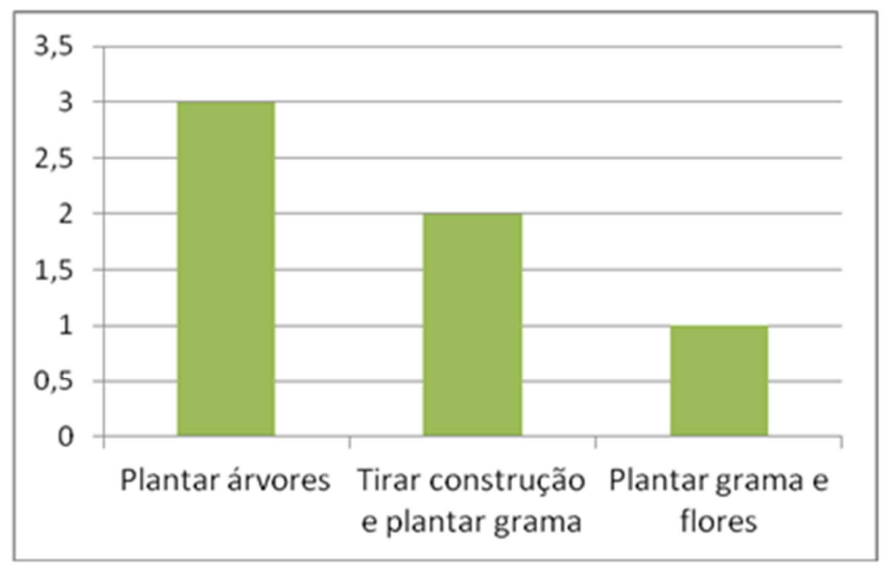

FIGURA 16 - MODIFICAÇÕES A SEREM FEITAS NOS LOTES QUE OCASIONARÃO O AUMENTO DA COBERTURA VEGETAL - SETOR CENSITÁRIO DO JARDIM SOCIAL.

FONTE: A autora (2012).

Notou-se o empenho de alguns moradores para aumentar o verde em seus lotes, uma vez que 2 proprietários pretendiam retirar construções a fim de abrir espaço para o plantio de grama.

\section{CONSIDERAÇÕES FINAIS}

Com esta pesquisa concluiu-se que não há uma tendência entre os proprietários de imóveis particulares, em nenhum dos setores censitários estudados, de manter, aumentar ou reduzir a cobertura vegetal de seus lotes. Pelo contrário, essas três ações apareceram praticamente na mesma proporção na parte cartográfica do trabalho nos dois setores avaliados, embora os proprietários acreditassem, em sua maioria, que tinham mantido a cobertura vegetal de seus lotes.

A semelhança de respostas aos questionários, comparando-se os setores censitários (como os principais motivos para o aumento ou redução do verde nos lotes, que foram basicamente os mesmos nos dois setores) demonstrou que a escolaridade não teve influência significativa nas decisões dos proprietários, aparecendo algo relacionado à 
questão ambiental somente em alguns motivos para o aumento ou a conservação da cobertura vegetal no lote, sobretudo no setor censitário do Jardim Social, de maior escolaridade. Uma possível explicação para esse fato pode ser o currículo escolar da época em que esses proprietários frequentavam a escola, pois apenas recentemente foram incluídos nas grades curriculares conteúdos relativos ao meio ambiente, ao desenvolvimento sustentável e à preservação dos recursos naturais.

Outro ponto a ser destacado desta pesquisa foi a relação do governo/prefeitura com esses proprietários, principalmente (e quase exclusivamente) os do setor censitário do Sítio Cercado. Ao realizar este trabalho ficou claro que a política de "obrigar" os moradores a manter uma porcentagem de seus terrenos com área verde é falha nesse setor, haja vista a quantidade de lotes sem nenhuma cobertura vegetal. Os motivos ficaram explícitos na pesquisa: a necessidade de construção (possivelmente em virtude do tamanho reduzido das casas e do lote) e de calçamento (pela facilidade de manutenção) faz com que o verde seja suprimido. Uma alternativa a essa política poderia ser a implantação de programas educativos com os moradores da região, o plantio de árvores adequadas nas calçadas em frente ao lote (uma área ótima a ser usada para esse fim, uma vez que não pode abrigar construções), que precisem de pouca manutenção e não atinjam os fios de luz e, principalmente, que sejam escolhidas pelos moradores, na tentativa de criar um "vínculo" entre eles e as árvores plantadas em frente a seus lotes. O que tem que ficar claro para a população é que a conservação de jardins e quintais, por menores que sejam, também contribui para a melhoria da qualidade ambiental e de vida da população das cidades.

\section{REFERÊNCIAS}

CAVALHEIRO, F.; NUCCI, J. C.; GUZZO P.; ROCHA, Y. T. Proposição de terminologia para o verde urbano.

Boletim Informativo da SBAU (Sociedade Brasileira de Arborização Urbana), ano VII, n. 3 - jul/ago/set de 1999, Rio de Janeiro, p. 7. 
GRUB, H. Ajardinamientos urbanos. Tradução José Luis Moro Carreño. Barcelona: Gustavo Gili S.A, 1986.

MARTINS JR, O. P. Uma cidade ecologicamente correta. Goiânia: AB, 1996.

MASCARÓ, L.; MASCARÓ, J. Vegetação urbana. 1 ed. Porto Alegre: L.Mascaró,J.Mascaró, 2002.

$\mathrm{NUCCl,} \mathrm{J.} \mathrm{C.} \mathrm{(Org.).} \mathrm{Planejamento} \mathrm{da} \mathrm{Paisagem} \mathrm{como} \mathrm{subsídio} \mathrm{para} \mathrm{a} \mathrm{participação} \mathrm{popular} \mathrm{no}$ desenvolvimento urbano. Estudo aplicado ao bairro de Santa Felicidade - Curitiba/PR. Curitiba: LABS/DGEOG/UFPR, 2010. e-book. Disponível em: <www.geografia.ufpr.br/laboratorios/labs>. Acesso em: 03/08/2012.

Qualidade ambiental e adensamento urbano: um estudo de Ecologia e Planejamento da Paisagem aplicado ao distrito de Santa Cecília (MSP). Curitiba: Edição do autor, 2008. e-book. Disponível em: <www.geografia.ufpr.br/laboratorios/labs>. Acesso em 29/01/2012.

PALAZZO JR., J. T.; BOTH, M. C. A natureza no jardim: um guia prático de jardinagem ecológica e recuperação de áreas degradadas. Porto Alegre: Sagra, 1989.

PEREIRA, M. C. B. Política para a conservação de áreas verdes urbanas particulares em Curitiba percepção dos proprietários de imóveis na bacia hidrográfica do rio Belém. $135 \mathrm{f}$. Dissertação (Mestrado em Engenharia Florestal) - Setor de Ciências Agrárias, Universidade Federal do Paraná, Curitiba, 2004.

SIPINSKI, E. A. B.; HOFFMANN, P. M. (Orgs). Cultura e biodiversidade nos Jardins de Curitiba. Curitiba: SPVS, 2010. 